\title{
Study on the Cost of Biomass Power Generation
}

\author{
Qi Gao ${ }^{1, a}$ \\ ${ }^{1}$ School of Renewable Energy, North China Electric Power University, Beijing, China \\ agq111628@126.com
}

Keywords: biomass energy, Biomass burning power generation, electricity cost Abstract. The development of biomass energy has been attracting attentions from all over the world. Biomass burning power generation is the main way to utilize the biomass energy with high cost of electricity. Based on the relevant analysis, the characteristics of the components of the electricity cost and the reasons leading to the high costs are studied in this paper. In addition, suggestions are proposed in terms of the issue of high electricity cost.

\section{Introduction}

With the rapid development of the global industrial process, the consumption of fossil energy is increasing. The utilization of fossil energy is one of the important factors to cause the global climate change. In order to cope with the issue of global climate change to achieve the sustainable development, it has become a common choice for all countries to develop renewable energy. As an important renewable energy resource, biomass energy has been paid great attention by countries all over the world.

As a powerful country in the world, China has been attaching great importance to the development of biomass energy. The 13th Five-Year Plan is an important transformation and upgrading period of energy during which the biomass energy is facing an important opportunity for its industrial development.

\section{Characteristics of Biomass Energy development in China}

The biomass energy resources of China are rich which mainly include the surplus materials by processing of straw and agricultural products, livestock residues, urban living garbage, industrial organic wastes and organic waste water [1]. With the further development of the construction of ecological civilization as well as agriculture and forestry industry in China, the level of the utilization of biomass energy in China has been increasing significantly.

Compared with developed countries, the technology of household biogas digester in China is at an advanced level in the world. And the anaerobic digestion technology of organic waste water and utilization of household biogas digester are becoming more and more mature. In addition, with the great advantage of a large amount of micro-algae planting resources, currently the overall development technology of algae energy in China has gradually reached the international advanced level. However, since the technology of biomass power generation in China started late, biomass direct combustion power generation makes up a relatively small share of the national electricity generation quantity with a small-scale generation technology. The lack of core technology and equipment, the difficulties in collecting, storing and transporting straw, high energy consumption and high electricity cost all hamper the development of biomass power generation [2]. Therefore, there is still a long way to go in continuously improving the utilization of biomass resources in China.

\section{Cost analysis of biomass power generation}

There are three ways to utilize Biomass energy which include direct combustion, thermochemical conversion and biochemical conversion. Biomass direct combustion is the main way to utilize biomass energy utilization in china. Taking the biomass direct combustion power generation as an 
example to analyze the cost structure of biomass fuel power generation, the following results can be obtained.

\subsection{The overall cost of biomass power generation is higher than thermal power generation}

The construction and investment cost of biomass power plants are two times as high as thermal power generation plants. In addition, since the cost of straw power generation is out of control, the quantity or cost control of fuel supply is more uncertain which results in that biomass power generation cost is far higher than thermal power.

\subsection{Fuel cost is a major component of the biomass power generation cost}

The power generation cost basically comprises of the investment cost, fuel cost as well as the operation and maintenance cost of the power plant. The cost of Biomass direct combustion power generation in China is shown in Fig 1.
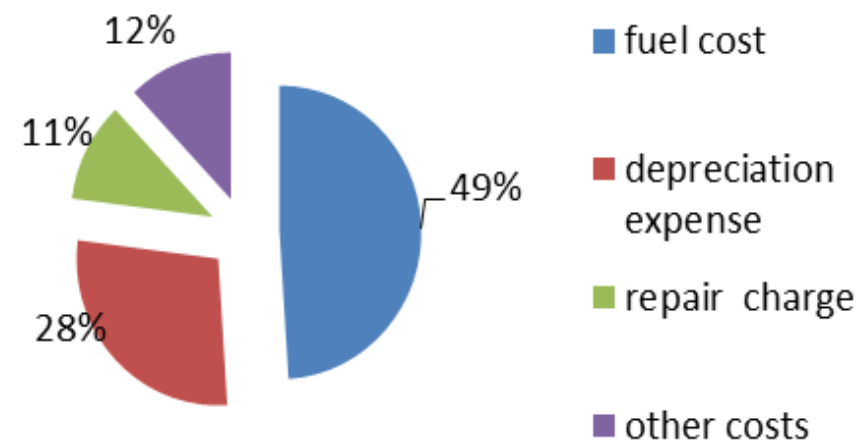

Fig. 1. The diagram of biomass direct combustion power generation cost

The fuel cost is the most important part which accounts for about $49 \%$ of the overall generation $\operatorname{cost}^{[3]}$.The estimations from different experts on the power generation cost based on biomass fuels can be significantly different due to the different scale of power plants and fuel prices. However, the fuel cost is a major component of the biomass power generation cost. The cost of $12 \mathrm{MW}, 20 \mathrm{MW}$ and $25 \mathrm{MW}$ direct combustion power generation is $0.75 \mathrm{CNY} / \mathrm{kWh}$ with $240 \mathrm{CNY} / \mathrm{t}$ straws, 0.834 $\mathrm{CNY} / \mathrm{kWh}$ with $300 \mathrm{CNY/t}$ straws and $0.403 \mathrm{CNY} / \mathrm{kWh}$ with $190 \mathrm{CNY} / \mathrm{t}$ straws, respectively. The calculated and analyzed result is shown in Fig 2.

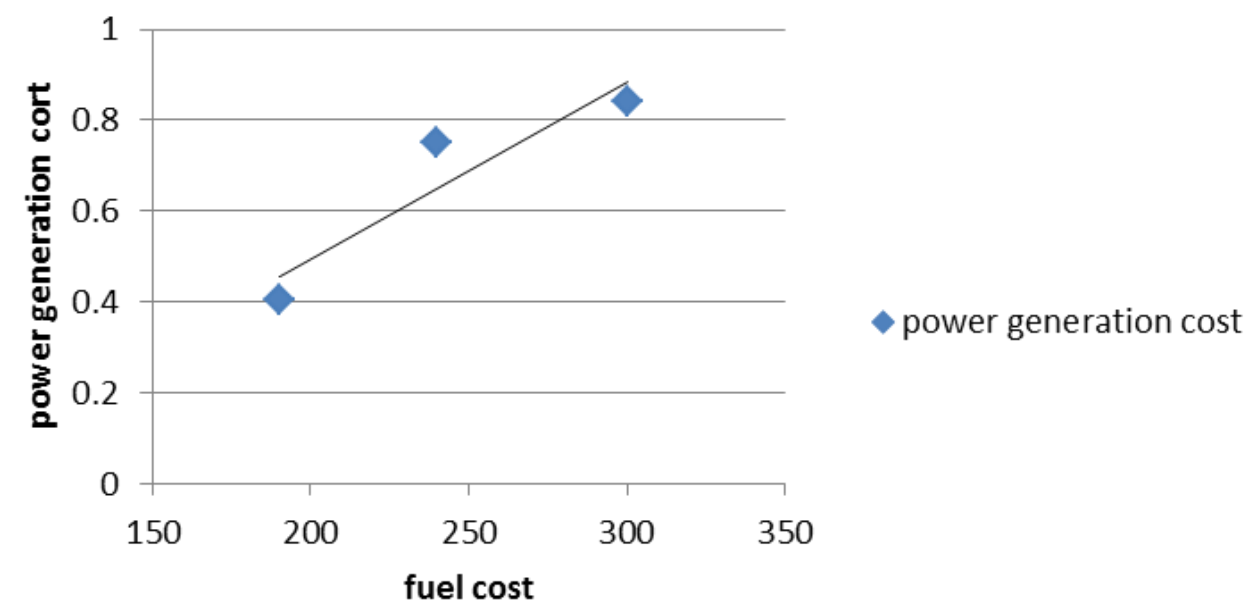

Fig. 2. The curve fitting of fuel cost and power generation cost 


\subsection{Transportation cost is the key to fuel cost}

The price of raw materials price consists of the cost of raw materials, transportation, processing and etc. The land per capita in China is small and the straw yield is still low and dispersed which makes the transportation of raw materials more difficult. Therefore, transportation cost has become the key to the price of raw materials. The vice president of North China Electric Power University, Tan Qinliang who also works for the research center of Beijing energy development, built the cost model of burning and collection of straws based on calculus in the paper titled 'Measurement model and empirical analysis of fuel collection cost for biomass power generation'. A $25 \mathrm{MW}$ biomass power plant is selected to calculate the fuel collection cost and the result shows that the transportation cost accounts for $44 \%$ which is the key component of the fuel cost ${ }^{[4]}$. Therefore, reducing the transportation cost is an effective way to cut the cost.

\subsection{The constraints of the game power supply}

Since the price-setting mechanism of energy and environment in China is still undeveloped with the different interests and targets of different parties, commercial capital is not available to get involved in the field of environmental protection at present. Due to the unstable biomass fuel supply, for this period of time, it's becoming more and more difficult to take biomass power generation as the main body of power supply. In addition, supply price of biomass power generation is higher than coal and electricity due to the pressure of economic assessment. With the rich coal resources at present, power supply mainly depends on coal and electricity which makes electricity power enterprises take less initiative to utilize biomass power generation.

\subsection{Centralized power plants makes poor profitability}

In recent years, the continuous increasing labor cost and stable electricity price cause poor profitability. Some local governments neglect the overall objective planning and guidance of industry development by considering the commercial investment attraction which eventually causes the irrational layout of regional projects. Centralized power plants will inevitably result in the high price and low quality of raw materials. At the same time, by employing the biomass power generation plants with different furnaces, the generation capacity and annual power utilization hours differ greatly. If the profit that power plants make by utilizing biomass fuels to generate electricity is less than the cost, enterprises will not be able to operate.

\section{Suggestions of improving the profit of biomass power generation}

It can be seen from the analysis that biomass power generation costs mainly consists of investment cost of power plants, fuel cost, maintenance cost and some other costs among which the fuel cost is the main component. While the transportation cost of raw materials is the key factor for the fuel cost. Therefore, reducing the cost of biomass energy utilization needs to be analyzed from different perspectives. And some relevant measures should be taken according to the primary influencing factors.

\subsection{Power plants harvest raw materials directly}

The traditional collection methods of biomass fuels are more complicated with long-time cycles which make farmers take less initiatives to sell straws and other raw materials. The improved method of collecting straws is that the local biomass power generation plant provides tillers to help farmers harvest the raw materials for free, and transport them directly to the power generation plants after packing which removes the redundant procedure of acquisition and resale by brokers. The proposed improved method can help to reduce the fuel cost and the harvesting cost for farmers. At the same time, the centralized disposal of raw materials will reduce pollution compared with the direct burning. 


\subsection{Local government controls the proportion of power supply}

The relevant local department should actively encourage enterprises to support the development of biomass energy. Under the circumstance of stable supply of biomass power generation, the proportion of biomass power generation in the overall power supply can be increased properly in order to keep a certain amount of power and profitable space. For resource-dependent areas, the supply price of biomass power generation is higher than coal and electricity. Relevant local department should urge the government to put national subsidies and founds in place in time, to make the biomass power generation enterprises have sufficient circulating capital and production capital. At the same time, the public should be encouraged to utilize biomass fuels and some other renewable resources. And some proper economic measures should be taken to improve the consuming desire for renewable resources which can decrease the proportion of coal and electricity in the power supply, and improve the producing activity of biomass power generation enterprises, for increasing their profitable space to promote the development of biomass power generation enterprises.

\subsection{Strengthen the supervision of biomass industry}

In recent years, it's reported that some small local power plants defrauded the government of state subsidies by the name of biomass power generation. Therefore, as for the application of project subsidies, the relevant department should investigate the enterprises for the actual condition of daily production including irregular investigation. The public should also be encouraged to expose the enterprises which defraud of subsidies by the name of biomass power generation. Crackdown on defrauding the state subsidies to make the biomass power generation enterprises have sufficient financial subsidies.

\section{Conclusion}

At present, China has made rapid progress in the field of biomass power generation. However, China is still on the initial development stage of biomass power affected by many factors, such as raw materials, processing technology and economic policies. The cost of biomass power generation is in general higher than thermal power due to more scattered feature, lower density and heating value of fuel than coal. Fuel cost is the main component of biomass power generation. And the transportation cost of raw materials is the key determinant of biomass fuel cost. In addition, on one hand, improving the collection and transportation of raw materials can reduce farmers' burden of harvesting straws to promote the production of biomass power generation enterprises. On the other hand, government should strengthen the supervision on biomass enterprise, promote the sustainable development of biomass industry as well as the vitality of related enterprises.

\section{References}

[1] Shen Xilin. Analysis on the influential factors of bio-energy development in China[J]. Journal of Southwest petroleum university (social sciences edition), 2010, Vol.4, No.1, pp.75-80.

[2] Liu Xiaojuan, Yin Weifeng. Biomass energy and its application technology in China and the world[J].Clean Coal Technology, 2008, pp.7-9.

[3] Ge Shaoying. Feasibility analysis of biomass electricity generation technology [D]. North China Electric Power University (Beijing), 2009.

[4] Tan Qinliang, Yang Haiping, Zhang Xingping, et al. Measurement model and empirical analysis of fuel collection cost for biomass power generation [J], Zhongguo Keji Luntan, 2014, No.5, pp.117-123. 